\title{
Knowledge Sharing Trust Level Measurement Adoption Model Based On Fuzzy Expert System
}

\author{
Olusegun Folorunso ${ }^{1}$ \\ ${ }^{1}$ Department of Computer Science, Federal University of Agriculture, Abeokuta, Nigeria \\ Correspondence: Olusegun Folorunso, Department of Computer Science, Federal University of Agriculture, \\ Abeokuta, Nigeria. E-mail: folorunsoo@funaab.edu.ng
}

Received: April 18, 2015

Accepted: April 28, 2015

Online Published: April 30, 2015

doi:10.5539/cis.v8n2p89

URL: http://dx.doi.org/10.5539/cis.v8n2p89

\begin{abstract}
In this paper, a fuzzy expert system-based Knowledge Sharing Trust Level(KSTL) measurement adoption model is presented. The KSTL was modeled using four input variables, developed from Technology Acceptance Model constructs namely; Perceived Trust Towards Competence, Perceived Trust Towards Benevolence, Perceived Trust Barrier for Sharing, External Cue Towards Trust to determine KSTL. A KSTL-fuzzy algorithm was developed using a trust metric equation at the preprocessing stage and implemented using Matlab 7.6.0 to compute KSTL crisp_value. The results obtained provided a useful understanding about the degree of trust among Community of Practice practicing knowledge-sharing. The proposed work was found to be dynamic, as the computed KSTL fluctuates with changes in the input variables. The simulated results demonstrate the effectiveness of the model in measuring trust level in knowledge-sharing applications.
\end{abstract}

Keywords: Knowledge Sharing, Knowledge Sharing Trust Level, Fuzzy Expert Systems, Technology Acceptance Model

\section{Introduction}

Nowadays, organisations are actively involved in the need to create and share new knowledge. However, these organisations tend to evaluate their environment for knowledge management (KM) based on trust. This work emphasizes on trust factor since it is the catalyst that motivates collaboration between peer groups in knowledge-sharing environment. But the trustworthiness of a peer group is a fuzzy concept that is dynamic and often changes with time or with environmental variation (Virginia and Rogier, 2005) and thus requires further study. Organisations have recognized that knowledge forms the nucleus for creating and sustaining competitive advantage and thus the need for knowledge management system such as the one proposed in this work. The sharing of knowledge constitutes a major problem in the domain of knowledge management because some individuals tend to monopolize or resist sharing their knowledge within their peer group. However, the findings of (Zadjabbari et al, 2010; Sabrima 2006; Peyman et al, 2013) were used as benchmark for our proposed fuzzy expert system model. A fuzzy expert system can be defined as the encoding of fuzzy rules and procedures into a user interface to perform fuzzy inferences. In simple term, fuzzy expert system encode the knowledge of an expert in the form of rules from the domain of knowledge sharing to produce inference via an interface. In this paper, Technology Acceptance Model (TAM) was adapted, which incorporates intention to share knowledge between knowledge sources and knowledge seekers.

$\mathrm{Xu}$, Feng \& Zhao (2007) in their paper confirm that trust is seen as a fuzzy uncertainty concept while, Parikshit et al (2014) presents fuzzy approach to the trust calculations that deals with the linguistic information of devices to address access control in the IoT (Internet of Things). The calculations of successful and unsuccessful interactions lie between -1 and +1 . The work uses trapezium membership function with 27 possible rules out of which 9 rules were taken into consideration.

Furthermore, it appears KSTL measurement adoption model based on fuzzy expert system with trust metric equation to enhance the quality of knowledge sharing decision has not been well researched. Trust metric equation is an access control strategy culled from (Patnaik et al, 2006).

In this work, four KSTL measurement metrics were used such as: PTTC, PTTB, PTBS and ECTT with the adoption of a trust metric equation from (Patnaik, et al., 2006) at the pre-processing stage to ensure quality 
control.

The rest of the paper is structured as follows. Section 2 is on literature review. Section 3 is on research methodology, processing and data analysis, while section 4 covers simulation, results and discussions while section 5 covers conclusion and suggestions for future works.

\section{Literature Review}

Muneer et al, (2014) in their paper collected and analysed a total of 159 responses from respondents in different parts of Malaysia from 20 different palm oil manufacturing plants and finds the dimensions of perceived organizational support, organizational trust, and organizational commitment have positive mediating effect on knowledge-sharing behaviour. Eisenberger et al., 1986; Rhoades and Eisenberger, 2002; Shore and Shore, 1995 observed that, to get the dividends of improved work efforts and to meet socio-emotional needs, employees must develop a common perception about the organizations' values, their contributions and cares about their well-being. Perceived organizational support may improve the employees' feelings of obligations to help organization in the attainment of its goals, their demands and their sacrifice to organization so that the improved performance can be achieved (Eisenberger et al., 1986; Rhoades and Eisenberger, 2002; Shore and Shore, 1995). Moreso, perceived organizational support serves as basis for the trust in organizations so that extra efforts can be observed and rewarded on its behalf (Eisenberger et al., 1990; Shore and Shore, 1995). Chong et al, (2014) they also observed that knowledge sharing is important but a determinant to either the success or failure of knowledge management. The author's major aim is to find the obstacles to knowledge sharing in the petrochemical companies. The authors grouped these obstacles into potential individual knowledge sharing barriers, potential organizational knowledge sharing barriers and potential technological knowledge sharing barriers base on 500 questionnaires distributed among employees out of which 302 questionnaires were returned. The authors concluded that, Trust, knowledge, power, communication, organizational hierarchy and knowledge sharing technological systems have relationships with knowledge sharing. (He et al, 2014) constructed and evaluated a model that associates team cooperation and knowledge sharing resulting to team flexibility. The author tested the model empirically with data from 141 knowledge-intensive teams and the result showed that team cooperation had an indirect relationship with knowledge sharing. Moreover, knowledge sharing is seen as the disclosure of task information and to cooperate with colleagues to solve given problems, and trying to develop new ideas (Cummings, 2004). Knowledge sharing can become possible through face-to-face interaction or written correspondence or by relating with other experts, or recording and capturing knowledge for others (Cummings, 2004). Furthermore, (Cummings, 2004) pointed that knowledge management is based on knowledge adoption, knowledge repository, knowledge formalism, knowledge utilization, and the most important aspect is knowledge sharing. According to (Lee et al., 2006) cooperation from senior management present a positive effect on both quality and level of knowledge sharing based on employee's truthfulness to knowledge management. (Andrews and Delahaye, 2000) believe that organizational trust is needed for predicting knowledge-sharing behaviour of employees and behaviour. Moreover, organizational support for knowledge sharing can be demonstrated by learning from the past mistake of employees instead of allowing them to commit such mistake in the future (Teo, 2005).

\section{Methodology}

\subsection{Trust-Based Knowledge Sharing Adoption Model (TBKSAM)}

The purpose of this model is to determine the motives of people in sharing their knowledge and also to examine whether the combination of competence-based and benevolence-based trusts has effect on knowledge sharing (Zadjabbari, 2009).

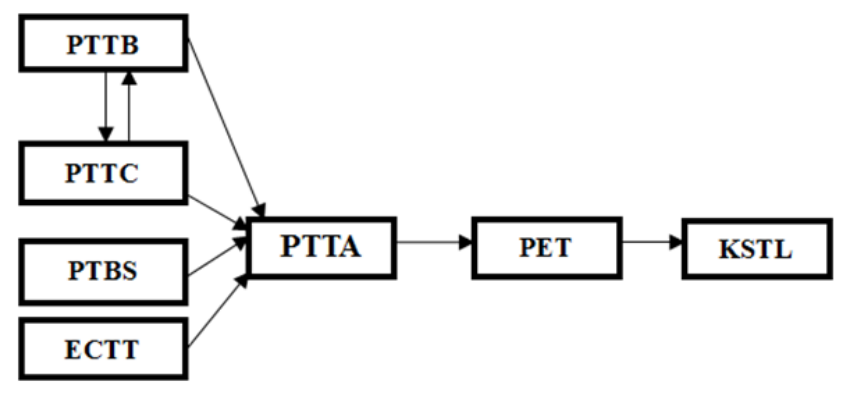

Figure 1. Trust-Based Knowledge Sharing Adoption Model (TBKSAM) 
Legend

PTTB: Perceived Trust Towards Benevolence

PTTC: Perceived Trust Towards Competence

PTBS: Perceived Trust Barrier for Sharing

ECTT: External Cue Towards Trust

PTTAB: Perceived Trust Towards Attitude and Behaviour

PET: Perceived Ease of Trust

KSTL: Knowledge Sharing Trust Level

The model in figure 1 takes into account, different factors affecting knowledge sharing such as trust in view of the confidence of the trusting agents, both its role as Knowledge seeker and Knowledge receiver.

PET: is the degree of confidence, trust or willingness between the knowledge source and the knowledge seekers (Davis, 1989 and Davies et al, 1989). PTTAB: is the level of trust prediction towards understanding the behavior and intention of a person that will occur (Taylor and Todd, 1995; Venkatesh and Davies, 2000, Huang, 2010). PTTC: is the perception about the ability or the degree of trust in which an individual believes that another person is knowledgeable or experienced in a given subject area (Connelly and Kelloway, 2003; Pavlou, 2006). PTTB: is the degree of willingness to share knowledge or the degree of trust to which an individual will not intentionally take advantage of a certain situation. PTBS: are the biases people have in trust toward knowledge sharing, (Rosenstock 1966, 1974; Huang, 2010). ECTT: are the external factors that affect trust and knowledge sharing (Huang, 2010; Strecher \& Rosenstock, 1997). KSTL: is the degree of willingness to share knowledge, based on the TBKSAM.

\subsection{Procedure for Data Collection}

The questionnaire used for knowledge capture consists of two parts. The first part captured the respondent demographic background such as gender, age, college and level. The second part of the questionnaire consists of the TBKSAM constructs. The model consists of perceived trust toward competence (PTTC), perceived trust toward benevolence (PTTB), perceived trust barrier for sharing (PTBS), external cue toward trust (ECT), perceived trust toward attitude and behavior (PTTAB), perceived ease of trust (PET) and knowledge sharing Trust Level (KSTL). The questions were answered using a five-point Likert scale, where $(1=$ strongly disagree to $5=$ strongly agree). All constructs were measured using existing and tested scales.

\subsection{Presentation and Analysis of Data}

This study uses a close-ended questionnaire as an instrument of collecting data for the analysis. In this questionnaire, 29 questions were grouped into seven constructs model of TBKSAM, and 4 models have been observed relative to the level of trust in knowledge sharing. The questionnaire used for knowledge capture consists of two parts. The first part described the respondent demographic background such as gender, age, college and level among the students of the Federal University of Agriculture, Abeokuta, Nigeria. The survey subject was mainly the registered students.

The analysis of the data collected through the questionnaire was in two parts. The first part of the analysis involved the use of descriptive statistics showing the percentage of the respondent's characteristics. Table 1 presents the descriptive statistics of the respondent characteristics based on the data captured using the questionnaire. It shows that the respondents were mostly people between age 21 and 25 which account for $53 \%$ of respondents. Both male (50.8\%) and female (49.2\%) actively participated in the survey with a close margin in gender counterparts.

Table 1. Profile of the Respondents

\begin{tabular}{|l|l|l|l|}
\hline Item & Frequency & Valid Percent & Cumulative Percentage \\
\hline Gender & & & \\
\hline Male & 66 & 50.8 & 50.8 \\
\hline female & 64 & 49.2 & 100 \\
\hline Age(years) & & & \\
\hline $16-20$ & 50 & 38.5 & 38.5 \\
\hline
\end{tabular}




\begin{tabular}{|l|l|l|l|}
\hline $21-25$ & 69 & 53 & 91.5 \\
\hline 26 and above & 11 & 8.5 & 100 \\
\hline COLLEGE & & & \\
\hline COLNAS & 50 & 38.5 & 38.5 \\
\hline COLENG & 8 & 6.2 & 44.6 \\
\hline COLANIM & 13 & 10 & 54.6 \\
\hline COPLANT & 16 & 4.6 & 59.2 \\
\hline COLAMURUD & 12 & 9.2 & 68.5 \\
\hline COLVET & 6 & 4.6 & 73.1 \\
\hline COLMAS & 10 & 7.7 & 80.8 \\
\hline COLFHEC & 14 & 10.8 & 91.5 \\
\hline COLERM & 11 & 8.5 & 100 \\
\hline Level & & & \\
\hline 100 level & 46 & 35.4 & 35.4 \\
\hline 200 level & 21 & 16.2 & 51.5 \\
\hline 300 level & 8 & 6.2 & 57.7 \\
\hline 400 level and above & 55 & 42.3 & 100 \\
\hline Total \% & $\mathbf{1 0 0}$ & $\mathbf{1 0 0}$ & $\mathbf{1 0 0}$ \\
\hline
\end{tabular}

The analysis did include cronbach's alpha which was as a measure of the internal consistency and reliability, which shows how closely related a set of items are as a group. The result indicated that the cronbach's alpha coefficient computed is greater than 0.6 in most of the constructs based on the benchmark suggested by Bagozzi and Yi (1988) except ECTT construct with 0.531. Table 2 shows the Cronbach's Alpha for Reliability and Validity Test.

Table 2. Cronbach's Alpha Results

\section{Reliability and Validity results}

\begin{tabular}{|l|l|l|}
\hline $\begin{array}{l}\text { Catego } \\
\text { ries }\end{array}$ & Measure & $\begin{array}{l}\text { Cronbach's } \\
\text { Alpha }\end{array}$ \\
\hline Perceived Trust Towards Benevolence (Connelly \& Kelloway, 2003; Pavlou,2006) \\
\hline PTTB1 & $\begin{array}{l}\text { I find it hard to take advantage of my colleagues experience even } \\
\text { though I know it }\end{array}$ & 0.767 \\
\hline PTTB2 & My friend trusts me enough to share their knowledge with me & \\
\hline PTTB3 & $\begin{array}{l}\text { I trust my friend even when he or she has enough experience of } \\
\text { my knowledge }\end{array}$ & \\
\hline PTTB4 & $\begin{array}{l}\text { I ask my friends for help because I know they will respect } \\
\text { confidentiality }\end{array}$ & \\
\hline Perceived Trust Towards Competence (Connelly \& Kelloway, 2003; Pavlou,2006)
\end{tabular}




\begin{tabular}{|c|c|c|}
\hline & them & \\
\hline ECTT2 & $\begin{array}{l}\text { My lecturers give me verbal praise and award mark when I share } \\
\text { my knowledge with other classmates. }\end{array}$ & \\
\hline ECTT3 & My lecturers always encourage us to engage in group discussion & \\
\hline \multicolumn{3}{|c|}{$\begin{array}{l}\text { Perceived Trust Towards Attitude and Behaviour (Taylor \& Todd, 1995; Venkatesh \& } \\
\text { Davis, 2000) }\end{array}$} \\
\hline $\begin{array}{l}\text { PTTA } \\
\text { B1 }\end{array}$ & $\begin{array}{l}\text { I feel the quality of my knowledge sharing effort is of great value } \\
\text { to the academic environment }\end{array}$ & 0.738 \\
\hline $\begin{array}{l}\text { PTTA } \\
\text { B2 }\end{array}$ & $\begin{array}{l}\text { The academic environment is genuine and sincere towards } \\
\text { knowledge sharing. }\end{array}$ & \\
\hline $\begin{array}{l}\text { PTTA } \\
\text { B3 }\end{array}$ & $\begin{array}{l}\text { The academic environments perform its role of sharing } \\
\text { knowledge well. }\end{array}$ & \\
\hline $\begin{array}{l}\text { PTTA } \\
\text { B4 }\end{array}$ & My friends are happy when I share my knowledge with them. & \\
\hline \multicolumn{3}{|c|}{ Perceived Ease of Trust (Davis, 1989 \& Davies et al, 1989) } \\
\hline PET1 & I require help, my friends do their best to help me & 0.728 \\
\hline PET2 & My friends are truthful in dealing with me & \\
\hline PET3 & $\begin{array}{l}\text { I trust my friends, when I asked them not to forward or share my } \\
\text { knowledge without my consent. }\end{array}$ & \\
\hline PET4 & I find it easy to share my knowledge among my friends. & \\
\hline PET5 & I frequently share my knowledge among others in the institution & \\
\hline \multicolumn{3}{|c|}{ Knowledge Sharing Trust Level (Taylor \& Todd, 1995) } \\
\hline KSTL1 & $\begin{array}{l}\text { My contribution to the school encourage and enable others to } \\
\text { develop new knowledge. }\end{array}$ & 0.778 \\
\hline KSTL2 & $\begin{array}{l}\text { The knowledge I share has a positive impact on my academic } \\
\text { performance. }\end{array}$ & \\
\hline KSTL3 & $\begin{array}{l}\text { Other communities members find my knowledge sharing } \\
\text { contribution to be useful. }\end{array}$ & \\
\hline KSTL4 & The knowledge I share brings development to the community. & \\
\hline KSTL5 & The institution reckons with knowledgeable contributor. & \\
\hline
\end{tabular}

\subsection{Functional Dependencies of TBKSAM}

However, the internal consistency and reliability was checked, (table 2) and it shows that the set of items are closely related as a group in an academic environment also the relations of the TBKSAM constructs was further tested by considering the functional dependencies definitions as discussed in (Korth and Silber schatz, 1986) below:

Definition 1: Functional Dependency $X \rightarrow Y$ holds on $R$ if in any legal relation $r(R)$, for all pairs of tuple $t_{1}$ and $\mathrm{t}_{2}$ in $\mathrm{r}$ such that $\mathrm{t}_{1}[\mathrm{X}]=\mathrm{t}_{2}[\mathrm{X}]$, it is also the case that $\mathrm{t}_{1}[\mathrm{Y}]=\mathrm{t}_{2}[\mathrm{Y}]$

Definition 2: Transitive Rule: if $X \rightarrow Y$ holds, and $Y \rightarrow Z$ holds, then $X \rightarrow Z$ holds

The two definitions was used to test the dependency of the constructs in fig. 1

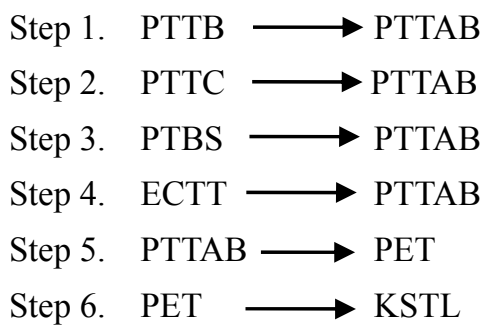

It was realized that PTTAB functionally depends on constructs (steps 1-4), see step 7

Step 7; [PTTB, PTTC, PTBS, ECTT] $\rightarrow$ PTTAB

It was also noted that (steps 5 and 6 ) are transitively dependent resulting in step 8

Step 8: $\quad$ PTTAB $\rightarrow$ KSTL 
Meanwhile, merging (steps 7 and 8) gives step 9

Step 9; [PTTB, PTTC, PTBS, ECTT] $\rightarrow$ KSTL

In summary, equation 1 can be used to deduce that four major constructs are the four inputs that derived the proposed KSTL model to be used in fuzzy expert systems environment.

\section{$\mathrm{KSTL}=\mathbf{f}(\mathrm{PTTB}, \mathrm{PTTC}, \mathrm{PTBS}, \mathrm{ECTT})$}

\subsection{Fuzzy Expert Systems Design}

The proposed KSTL-Fuzzy framework comprises the KSTL and fuzzy expert system. The trust metric equation computes the trust value of each of the KSTL inputs for reliability at the pre-processing module while KSTL value and decision are taken at post- processing module. Fig 2 shows the KSTL and Fuzzy expert system components incorporating into a single framework.

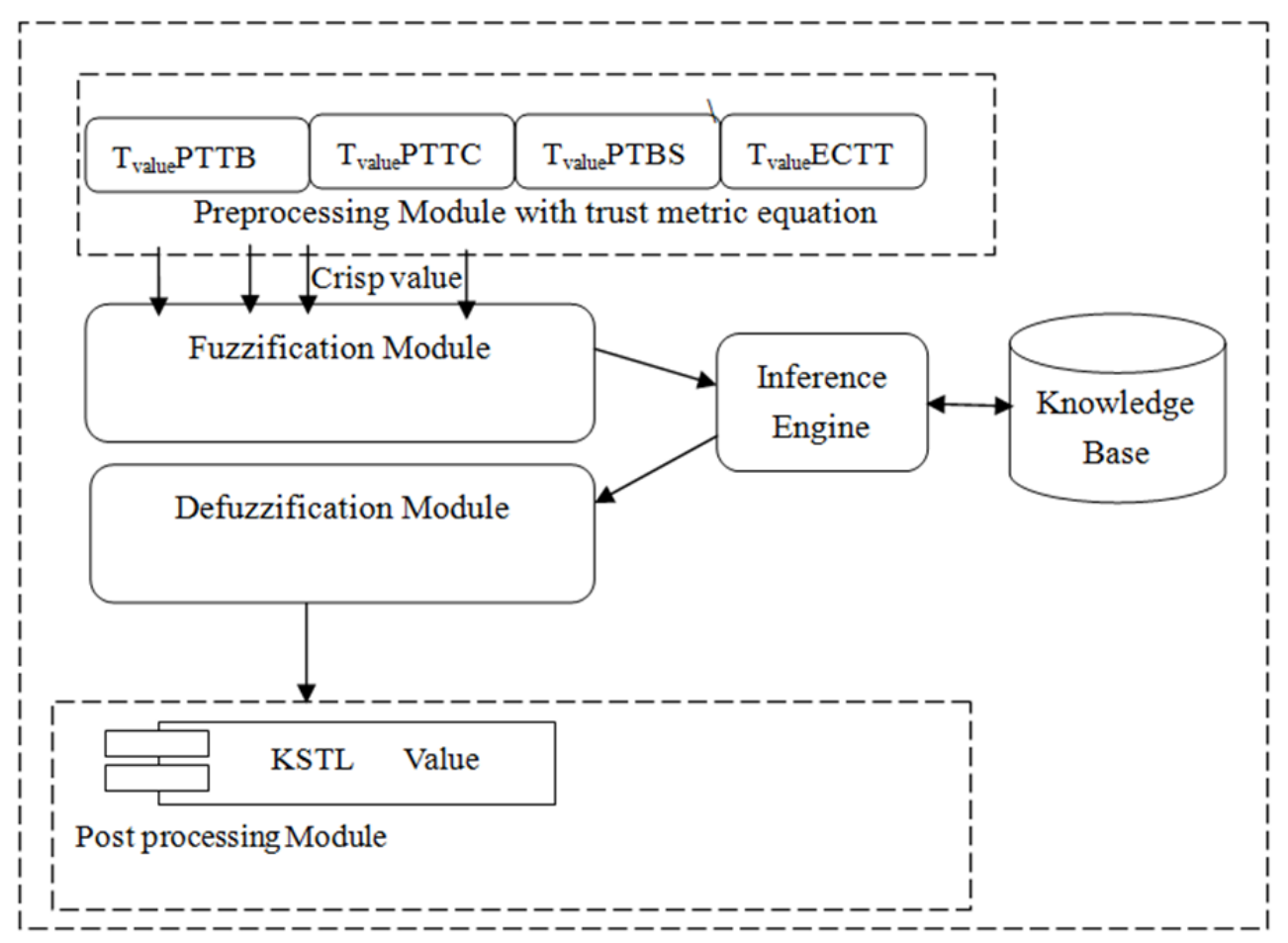

Figure 2. KSTL and Fuzzy Expert system Architectural design

\section{(a) Preprocessing module with KSTL trust policy}

KSTL trust policy decides the measurement of trust degree of PTTB, PTTC, PTBS and ECTT between trustee A and trustee B when performing tasks. The trust value of trustee A and trustee B is determined as they visit each other. A trust metric equation from (Patnaik, et al., 2006) was adapted so as to compute the trust values of the trustees. The $\boldsymbol{T}_{\boldsymbol{o}}$ is the average of the trust values of trustee A to trustee B on a visit and trustee B back to trustee A for each of the KSTL inputs [PTTB, PTTC, PTBS and ECTT] for n trials between trustee A and trustee B, $\boldsymbol{E}_{\boldsymbol{i}}$ is an events, action or service carried out between trustee $\mathrm{A}$ and trustee $\mathrm{B}[-1,+1]$ base on distrust and trust levels respectively. The value of the weight $\boldsymbol{W}_{\boldsymbol{i}}$ is assigned to each event $\boldsymbol{E}_{\boldsymbol{i}}$ between trustee A and trustee B and vice-versa (adapted from Patnaik et al, 2006). Linguistic variables are defined in the table 3 and the membership function for KSTL are shown in fig. 3 and 4.

$$
\begin{aligned}
& T_{\text {value }}(K S T L)=T_{o}+\frac{\sum_{i=0}^{n} W i E i}{\sum_{i=0}^{n} W i}+f(t) \\
& \quad \boldsymbol{E} \in[-\mathbf{1},+\mathbf{1}] \quad \boldsymbol{W} \in[\mathbf{0}, \mathbf{1}]
\end{aligned}
$$

$\boldsymbol{T}_{\boldsymbol{o}}$ is the initial trust value assigned to task between trustee A and trustee B. The initial value has a relation to the evaluation of trust value of a trustee. Hence, $T_{0}$ value has to be defined for a new and existing trustee for each KSTL activity.

The term $\mathbf{f}(\mathbf{t})$ is added to the equation to reflect any time-dependent activity (or inactivity) to suggest gain or loss 
of reliability. The $f(t)$ value represents error in the model when there is no feedback between the sending and receiving trustees due to a network being down or system itself is down. In our case $f(t)$ is computed as $\delta^{2} / n_{\mathrm{o}}$

The trust value is evaluated based on event performed by the trustees. Such events carry values and they are also weighty. An event can be negative if the trustee tries to act maliciously; such could be a failure to login or a trustee trying to cheat.

\section{(b) Fuzzification Module}

The fuzzification module of the fuzzy expert system takes the crisp_value and determines the degree to which these inputs belong to each of the appropriate fuzzy sets. The crisp_values of the input variable are converted into linguistic value.

In this work, four crisp input variables [PTTB, PTTC, PTBS, ECTT], are transformed into fuzzy sets as shown in table 3 with their linguistic variables and the output variable shown in table 4 with their membership function..

The membership function in this case is trapezoidal as is specified by four parameters $(a, b, c, d)$ as follows:

$$
\text { trapezoidal }(x ; a, b, c, d)=\left\{\begin{array}{lr}
0, & x \leq a \\
\frac{x-a}{b-a}, & a \leq x \leq b \\
1, & b \leq x \leq c \\
\frac{d-x}{d-c}, & c \leq x \leq d \\
0, & d \leq a
\end{array}\right\}
$$

An alternative expression using min and max:

$$
\text { trapezoidal }(x ; a, b, c, d)=\max \left(\min \left(\frac{x-a}{b-a}, 1, \frac{d-x}{d-c}\right), 0\right)
$$

Table 3. Variable and membership function

\begin{tabular}{|l|l|l|l|}
\hline Linguistic Variable & Fuzzy Set (Linguistic value) & Crisp Range & Fuzzy numbers \\
\hline PTTB, & Low & $\mu \leq-0.50$ & $(-1,-1 .-0.5,-0.1)$ \\
PTTC, & Moderate & $-0.1 \leq \mu \leq-0.25$ & $(-0.25,-0.1,0.25 .0 .5)$ \\
PTBS, & High & $\mu \geq 0.50$ & $(0.25,0.5,1,1)$ \\
ECTT & & \\
\hline
\end{tabular}

Table 4. Output variable and membership function

\begin{tabular}{|l|l|l|l|}
\hline Linguistic Variable(output) & Fuzzy Set (Linguistic value) & Crisp Range & Fuzzy numbers \\
\hline Knowledge sharing trust & Low & $\mu \leq-0.50$ & $(-1,-1 .-0.5,-0.1)$ \\
level & Moderate & $-0.1 \leq \mu \leq-0.25$ & $(-0.25,-0.1,0.25 .0 .5)$ \\
& High & $\mu \geq 0.50$ & $(0.25,0.5,1,1)$ \\
\hline
\end{tabular}

\section{(c) Fuzzy Inference System Design}

In achieving a good result, Mamdani's approach and a centroid method for defuzzification are used for the design of the fuzzy system. The system has four inputs and an output with trapezodial type of membership functions as shown in fig. 3 and fig.4. The output fuzzy sets of all rules are then combined to form a single fuzzy set for the output variable, KSTL e.g.

Rule: If (PTTB is high) and (PTTC is moderate) and (PTBS is moderate) and (ECTT is moderate) then (KSTL is high).

Data elicited are normalized and loaded using Load Data button into the ANFIS Editor GUI workspace. FIS are generated using grid partition algorithms with back propagation optimization method for testing using trapezium membership function type. Eighty-one rules were identified in rule editor's view which we later used in fuzzy environment. 


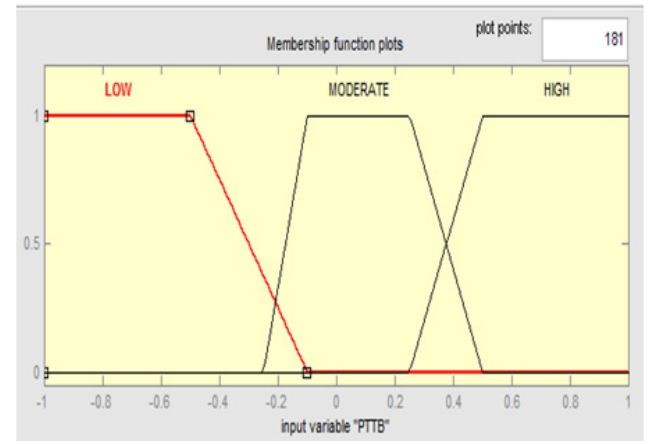

Figure 3. Membership Function for input PTTB

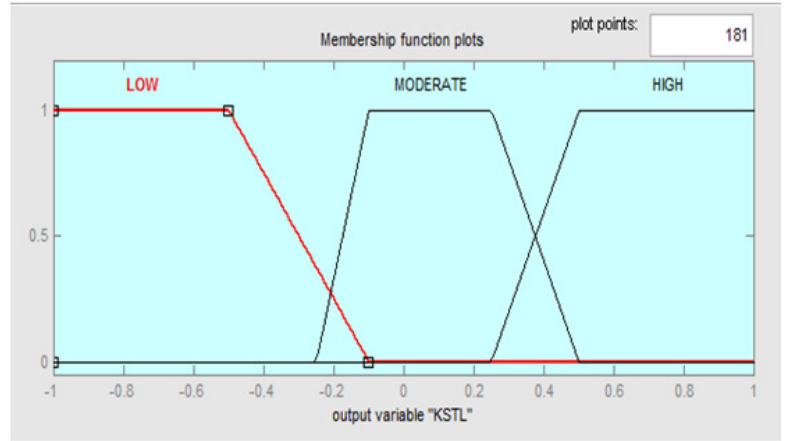

Figure 4. Membership Function for output KSTL

(d) Defuzzification: The next step is defuzzification and this help in evaluating the rules, but the final output of a fuzzy system has to be a crisp number. The input for the defuzzification process is the aggregate output fuzzy set and the output is a single number.

(e) Post processing module: This module evaluates the performance of the trustees involved and enables the decision maker to know the knowledge sharing trust level index and finally grant access. This stage does not deny trustee with a low level performance index. Every trustee in the environment is allowed to take part in the task but the decision maker will consider trustees whose contribution reach the accepted level to share knowledge.

\subsection{Kstl-Fuzzy Algorithm}

A kstl-fuzzy algorithm was developed using a trust metric equation at the preprocessing stage and later implemented using Matlab 7.6.0. The trust metric equation accept four inputs; PTTB, PTTC, PTBS and ECTT in order to derive Tvalues for each input. These Tvalues now represent kstl_crisps values for the fuzzy inference system using Mamdani technique and later defuzzified using centroid. However, there is need to have an agreed threshold trust value for decision making to be used in granting access or denying access to sharing lies between and $[-1,+1]$.

\section{INPUT Parameter:}

\section{[1]PTTB, PTTC, PTBS and ECTT}

[2] Events $E_{\mathrm{i}}$

[3] Initial Trust value $T_{o}$

[4] Weight $W_{i}$,

[5] $F(t)$;

\section{OUTPUT:}

[1] Priority value // crisp value

\section{Begin}

Step 1: Initialization

$T_{o}$ // initial value of the trustee

Dval $=\left[\begin{array}{ll}-1.0 & 1.0\end{array}\right] / /$ trust level defined by the trustee between -1.0 and 1.0

Max val. of Event $=1.0$, Min val. of Event $=-1.0$,

Max val. of weight $=1$, Min val. of weight $=0.0$

Step 2: For $i=1$ to ArrayLength

Event $E[i]=$ Generate Random(Event Max, Event Min)

Weight $W[i]=$ Generate Random(Weight Max, Weight Min)

$i=i+1$

end for Loop 
Step 3: $\quad T_{o}=\frac{\sum_{i=1}^{n} P T T B i}{n}$

for $i=1$ to ArrayLength

Begin

Compute $T_{\text {value }}($ PTTB $)=T_{o}+\frac{\sum_{i=0}^{n} W i E i}{\sum_{i=0}^{n} W i}+f(t)$

Write $\left\{\left(\mathrm{T}_{\text {value }},(\mathrm{PTTB})\right\} \quad / /\right.$ Compute $\mathrm{T}_{\text {value }}$ for PTTB,

end for Loop;

Step 4: $\quad T_{o}=\frac{\sum_{i=1}^{n} \text { PTTCi }}{n}$

for $i=1$ to ArrayLength

Begin

Compute $T_{\text {value }}(P T T C)=T_{o}+\frac{\sum_{i=0}^{n} W i E i}{\sum_{i=0}^{n} W i}+f(t)$

Write $\left\{\mathrm{T}_{\text {value }},(\mathrm{PTTC})\right\} \quad / /$ Compute $\quad \mathrm{T}_{\text {value }}$ for PTTC

end for Loop;

Step 5: $\quad T_{o}=\frac{\sum_{i=1}^{n} \text { PTBSi }}{n}$

for $i=1$ to ArrayLength

Begin

Compute $T_{\text {value }}(P T B S)=T_{o}+\frac{\sum_{i=0}^{n} W i E i}{\sum_{i=0}^{n} W i}+f(t)$

Write $\left\{\left(\mathrm{T}_{\text {value }},(\mathrm{PTBS})\right\} \quad / /\right.$ Compute $\mathrm{T}_{\text {value }}$ for PTBS

end for Loop;

Step 6: $\quad T_{o}=\frac{\sum_{i=1}^{n} E C T T i}{n}$

for $i=1$ to ArrayLength

Begin

Compute $T_{\text {value }}(E C T T)=T_{o}+\frac{\sum_{i=0}^{n} W i E i}{\sum_{i=0}^{n} W i}+f(t) / /$

Write $\left\{\left(\mathrm{T}_{\text {value }}, \mathrm{ECTT}\right)\right\} \quad / /$ Compute $\mathrm{T}_{\text {value }}$ for ECTT

end for Loop;

Step7: convert $T_{\text {value }}$ of PTTB, PTTC, PTBS, ECTT to fuzzy value / four input value of the fuzzy system

Step 8: Evaluate the rules in the rule base // fuzzy inference engine

Step 9: Combine the results of each rule // Using mamdani rules

Step 10: Convert the output data to non-fuzzy values // Defuzzification using centroid

Step 11: kstl_crisp_value $=$ Defuzzified value using centroid in step 10

Step12: if kstl_crisp_value $\geq$ Dvalue /II Knowledge trustees defined value (dvalue) between ---1.0 and 1.0

Step 13: Access granted and knowledge shared; / access granted to a trustee that falls in a defined range

else

access denied and knowledge not shared;

end 


\subsection{Simulation, Results and Discussion}

\subsection{Simulation and Results}

Table 5 to 7 shows the initial values of trust $\mathrm{T}_{0}$ for the four input constructs, values of $\mathrm{E}$ and $\mathrm{W}$ for the trials and the final results of the four constructs respectively.

Table 5. Initial values of $\mathrm{T}_{\mathrm{o}}$ for PTTB, PTTC, PTBS and ECTT

\begin{tabular}{|c|c|c|c|c|}
\hline Trials & $\begin{array}{l}\text { PTTB_ } \\
\text { avg }\end{array}$ & $\begin{array}{l}\text { PTTC_ } \\
\text { avg }\end{array}$ & $\begin{array}{l}\text { PTBS_ } \\
\text { avg }\end{array}$ & $\begin{array}{l}\text { ECTT_ } \\
\text { avg }\end{array}$ \\
\hline 1 & 0.51 & 0.84 & 0.61 & 0.65 \\
\hline 2 & -0.45 & 0.73 & 0.18 & 0.87 \\
\hline 3 & -0.08 & 0.06 & -0.10 & 0.77 \\
\hline 4 & 0.69 & 0.32 & 0.21 & 0.48 \\
\hline 5 & 0.25 & -0.24 & 0.20 & 0.33 \\
\hline 6 & 0.21 & 0.27 & 0.34 & 0.52 \\
\hline 7 & 0.50 & 0.18 & 0.22 & 0.29 \\
\hline 8 & 0.29 & 0.68 & -0.34 & 0.58 \\
\hline 9 & 0.08 & 0.92 & 0.02 & 0.43 \\
\hline 10 & $\underline{0.52}$ & 0.35 & 0.49 & 0.34 \\
\hline STD $=$ & 0.338372 & 0.37242 & 0.274778 & 0.192891 \\
\hline$f(t)=$ & 0.01145 & 0.01387 & 0.00755 & 0.003721 \\
\hline
\end{tabular}

Table 6: Values of $\mathbf{E}$ and $\mathbf{W}$ for the trials

\begin{tabular}{|c|c|c|c|}
\hline Trials & $\mathbf{w}$ & $E$ & $\mathbf{W}^{*} \mathrm{E}$ \\
\hline 1 & 0.20 & 0.47 & 0.09 \\
\hline 2 & 0.64 & -0.96 & -0.61 \\
\hline 3 & 0.66 & -0.72 & -0.48 \\
\hline 4 & 0.84 & 0.52 & 0.43 \\
\hline 5 & 0.59 & -0.28 & -0.16 \\
\hline 6 & 0.90 & 0.37 & 0.33 \\
\hline 7 & 0.40 & -0.48 & -0.19 \\
\hline 8 & 0.95 & 0.83 & 0.79 \\
\hline 9 & 0.85 & 0.33 & 0.28 \\
\hline 10 & $\underline{0.75}$ & $\underline{0.27}$ & 0.20 \\
\hline Total & 6.79 & 0.34 & 0.68 \\
\hline
\end{tabular}

Table 7. Final result of PTTB, PTTC, PTBS and ECTT

\begin{tabular}{|l|r|r|r|r|}
\hline Trials & \multicolumn{1}{l}{$\begin{array}{l}\text { PTTB_ } \\
\text { avg }\end{array}$} & \multicolumn{1}{l}{$\begin{array}{l}\text { PTTC_ } \\
\text { avg }\end{array}$} & \multicolumn{1}{l}{$\begin{array}{l}\text { PTBS_ } \\
\text { avg }\end{array}$} & \multicolumn{1}{l}{$\begin{array}{l}\text { ECTT_ } \\
\text { avg }\end{array}$} \\
\hline $\mathbf{1}$ & 0.63 & 0.95 & 0.72 & 0.76 \\
\hline $\mathbf{2}$ & -0.33 & 0.84 & 0.29 & 0.97 \\
\hline $\mathbf{3}$ & 0.03 & 0.17 & 0.01 & 0.87 \\
\hline $\mathbf{4}$ & 0.81 & 0.44 & 0.32 & 0.58 \\
\hline $\mathbf{5}$ & 0.37 & -0.12 & 0.31 & 0.43 \\
\hline $\mathbf{6}$ & 0.32 & 0.38 & 0.45 & 0.62 \\
\hline $\mathbf{7}$ & 0.61 & 0.29 & 0.33 & 0.40 \\
\hline $\mathbf{8}$ & 0.40 & 0.79 & -0.23 & 0.68 \\
\hline $\mathbf{9}$ & 0.19 & 1.04 & 0.13 & 0.54 \\
\hline $\mathbf{1 0}$ & 0.64 & 0.46 & 0.60 & 0.44 \\
\hline
\end{tabular}

The membership function editor displays a graphical representation of the trust level, MF. In this paper, the membership function of each criterion ranges as specified in tables ( 3 and 4). There are 81 rules used with 4 inputs, and 1 output. Fig. 5 shows that the model is dynamic, and fuzzy rules are used to measure Knowledge Sharing Trust Level. The input variables PTTB, PTTC, PTBS and ECTT could have low trust, moderate trust, and high trust. Knowledge Sharing Trust Level has an output, which could be low, moderate, and high. The Fuzzy Expert System is designed using Matlab 7.6.0; and and can be used to measure knowledge sharing trust level of an individual based on the input variables as it changes; in any direction of trust which signifies that the model is dynamic. The fig. 5 is interpreted as if the PTTB is positively high(0.63), PTTC as positively high (0.95), PTBS as positively high (0.72), and ECTT as positively high (0.76) resulting into KSTL to be positive and high with the value 0.688 i.e. $68.8 \%$. 


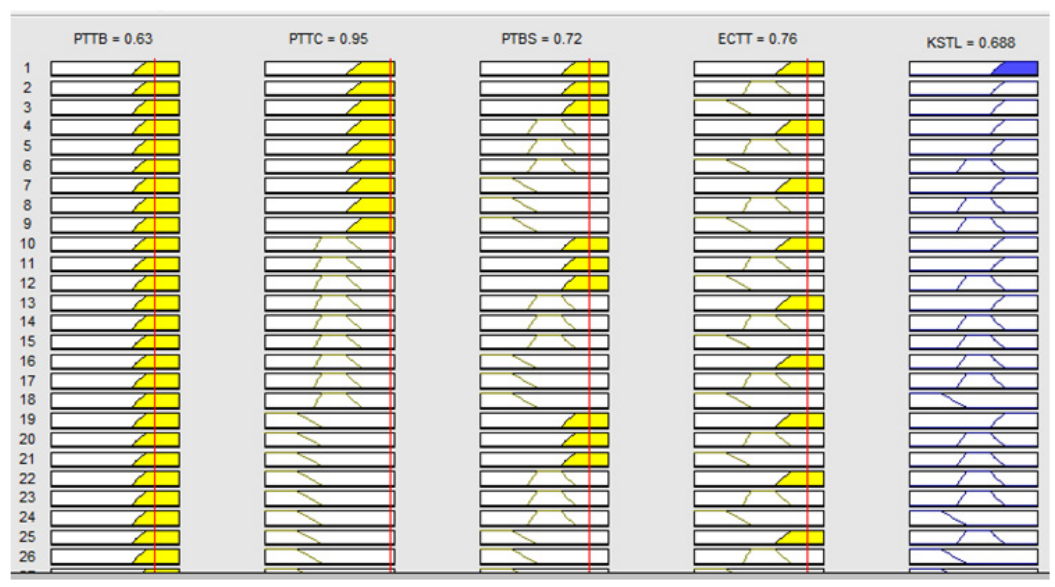

Figure 5. the effect of input variables on knowledge sharing

The Fuzzy Expert System model is designed using Matlab 7.6.0 ; and, as it can be used to measure knowledge sharing trust level (intention) of an individual based on the input variables as it changes; in any direction of trust which signifies that the model is dynamic.

Tables 8 \& 9 shows the results of simulation of ten trial runs with decision taking for KSTL crisp vale (Dvalue $>$ $0.00)$. It was noted that Dvalue is assumed to be knowledge trustees' agreed defined value.

Table 8. Initial value To for all PTTB, PTTC, PTBS and ECTT without using trust metric equation

\begin{tabular}{|l|r|r|r|r|r|r|}
\hline Trials & \multicolumn{1}{|l|}{ PTTB_avg } & \multicolumn{1}{l|}{$\begin{array}{l}\text { PTTC_ } \\
\text { avg }\end{array}$} & \multicolumn{1}{l|}{ PTBS_avg } & \multicolumn{1}{l|}{ ECTT_avg } & \multicolumn{1}{l|}{$\begin{array}{l}\text { KSTL } \\
\text { crisp } \\
\text { value }\end{array}$} & $\begin{array}{l}\text { Knowledge sharing } \\
\text { Decision } \\
\text { (Dvalue> 0.00) }\end{array}$ \\
\hline $\mathbf{1}$ & 0.51 & 0.84 & 0.61 & 0.65 & 0.688 & Shared \\
\hline $\mathbf{2}$ & -0.45 & 0.73 & 0.18 & 0.87 & 0.000 & Denied \\
\hline $\mathbf{3}$ & -0.08 & 0.06 & -0.10 & 0.77 & 0.000 & Denied \\
\hline $\mathbf{4}$ & 0.69 & 0.32 & 0.21 & 0.48 & 0.621 & Shared \\
\hline $\mathbf{5}$ & 0.25 & -0.24 & 0.20 & 0.33 & 0.000 & Denied \\
\hline $\mathbf{6}$ & 0.21 & 0.27 & 0.34 & 0.52 & 0.000 & Denied \\
\hline $\mathbf{7}$ & 0.50 & 0.18 & 0.22 & 0.29 & 0.200 & Shared \\
\hline $\mathbf{8}$ & 0.29 & 0.68 & -0.34 & 0.58 & 0.640 & Shared \\
\hline $\mathbf{9}$ & 0.08 & 0.92 & 0.02 & 0.43 & 0.000 & Denied \\
\hline $\mathbf{1 0}$ & $\mathbf{0 . 5 2}$ & $\mathbf{0 . 3 5}$ & $\mathbf{0 . 4 9}$ & $\mathbf{0 . 3 4}$ & $\mathbf{0 . 6 3 5}$ & Shared \\
\hline STD $=$ & $\mathbf{0 . 3 3 8 3 7 2}$ & $\mathbf{0 . 3 7 2 4 2}$ & $\mathbf{0 . 2 7 4 7 7 8}$ & $\mathbf{0 . 1 9 2 8 9 1}$ & & \\
\hline $\mathbf{f}(\mathrm{t})=$ & $\mathbf{0 . 0 1 1 4 5}$ & $\mathbf{0 . 0 1 3 8 7}$ & $\mathbf{0 . 0 0 7 5 5}$ & $\mathbf{0 . 0 0 3 7 2 1}$ & & \\
\hline
\end{tabular}

Table 9. Final result for all PTTB, PTTC, PTBS and ECTT with trust metric equation

\begin{tabular}{|l|r|r|r|r|r|c|}
\hline Trials & $\begin{array}{l}\text { PTTB_ } \\
\text { avg }\end{array}$ & $\begin{array}{l}\text { PTTC_ } \\
\text { Avg }\end{array}$ & $\begin{array}{l}\text { PTBS_ } \\
\text { Avg }\end{array}$ & $\begin{array}{l}\text { ECTT_ } \\
\text { Avg }\end{array}$ & $\begin{array}{l}\text { KSTL_crisp } \\
\text { value }\end{array}$ & $\begin{array}{l}\text { Knowledge sharing Decision } \\
\text { Dvalue> 0.00) }\end{array}$ \\
\hline $\mathbf{1}$ & 0.63 & 0.95 & 0.72 & 0.76 & 0.688 & Shared \\
\hline $\mathbf{2}$ & $\mathbf{- 0 . 3 3}$ & 0.84 & 0.29 & 0.97 & 0.000 & Denied \\
\hline $\mathbf{3}$ & 0.03 & 0.17 & 0.01 & 0.87 & 0.000 & Denied \\
\hline $\mathbf{4}$ & 0.81 & 0.44 & 0.32 & 0.58 & 0.673 & Shared \\
\hline $\mathbf{5}$ & 0.37 & $-\mathbf{0 . 1 2}$ & 0.31 & 0.43 & 0.470 & Shared \\
\hline $\mathbf{6}$ & 0.32 & 0.38 & 0.45 & 0.62 & 0.647 & Shared \\
\hline $\mathbf{7}$ & 0.61 & 0.29 & 0.33 & 0.40 & 0.456 & Shared \\
\hline $\mathbf{8}$ & 0.40 & 0.79 & $-\mathbf{0 . 2 3}$ & 0.68 & 0.650 & Denied \\
\hline $\mathbf{9}$ & 0.19 & 1.04 & 0.13 & 0.54 & 0.000 & Shared \\
\hline $\mathbf{1 0}$ & 0.64 & 0.46 & 0.60 & 0.44 & 0.675 & \\
\hline
\end{tabular}


We extended further by comparing the output result of a 4-fuzzy input system (i.e. system enhanced with trust metric) to a 4-input input system without passing through trust metric equation. The result however (as shown in (tables 8 and 9), shows the effect of trust metric as a means of quality control in the KSLT, which shows its effect on the overall performance.

The output values in tables ( 8 and 9) serve as the KSLT decision values for trustees to share knowledge with priority value (Dval) let say Dval $=0.00$ as defined jointly by the trustees. It shows that knowledge can be shared among 50\% (table 8) of the trustees and when trust metric is used, it changes to $70 \%$ (table 9).

\section{Conclusions and Suggestions for Future Work}

Trust level measurement is crucial to the success of many organizations, especially when knowledge is being shared. This paper presents a fuzzy expert system used to measure trust level based on PTTB, PTTC, PTBS, and ECTT with intension that knowledge source are benevolent and competent. We have been able to use functional dependency graph to decompose the relationships which was later used as input to fuzzy inference system.

The results from this paper provide useful understanding of the impact of trust in knowledge sharing efficacy and analysing the sensitivity of trust in knowledge sharing. It means that knowledge sharing should be about creating an environment in which people are able to distinguish whether their colleagues are both knowledgeable and willing to extend their knowledge to the benefit of others. The application of fuzzy expert system is highly recommended for estimating the level of trust in knowledge sharing due to its ability to adapt to the environment and generate fuzzy rules that are to be interpreted and evaluated. As part of future work, we intend to use other soft computing techniques such as artificial neural networks to predict KSTL and genetic algorithm to determine optimal KSTL construct among the trustees.

\section{References}

Andrews, K., \& Delahaye, B. L. (2000). Influences on knowledge processes in organizational learning: The psychological filter. Journal of Management Studies, 37(6), 797-810.

Chong, C. W., \& Jamshid, B. (2014). Challenges of knowledge sharing in the petrochemical industry, Knowledge Management \& E-Learning, 6(2), 171-187.

Connelly, C. E., \& Kelloway, E. K. (2003). Predictors of employees' perceptions of knowledge sharing cultures. Leadership \& Organization Development Journal, 24(5/6), 294-301.

Cummings, J. N. (2004). Work groups, structural diversity, and knowledge sharing in a global organization. Management Science, 50(3), 352-364.

Davies, F. D. (1989). Perceived Usefulness, Perceived Ease of Use and User Acceptance of Information Technology. MIS Quarterly, 13(3), 319-340. http://dx.doi.org/10.1016\%2Fj.jbi.2009.06.001

Davis, F. D., Bagozzi, R. P., \& Warshaw, P. R. (1989). User Acceptance of Computer Technology: A Comparison of Two Theoretical Models. Management Science, 35(8), 982-1003. http://dx.doi.org/10.1287/mnsc.35.8.982

Eisenberger, R., Fasolo, P. M., \& Davis-LaMastro, V. (1990). Perceived organizational support and employee diligence, commitment, and innovation. Journal of Applied Psychology, 75(1), 51-59. http://dx.doi.org/10.1016/j.sbspro.2011.10.215.

Eisenberger, S., Huntingdon, R., Hutchinson, S., \& Sowa, D. (1986). Perceived organizational support. Journal of Applied Psychology, 71(3), 500-507.

He, H. W. Yehuda, B., \& Lin, C. P. (2014). Modeling team knowledge sharing and team flexibility: The role of within-team competition. Human Relations, 67(8) 947-978.

Huang, J. (2010). Remote Health Monitoring Adoption Model Based on Artificial Neural Networks. Expert Systems with Applications, 37, 307-314. http://dx.doi.org/10.1016/j.eswa.2009.05.063

Korth, H. F., \& Silberscatz (1986). Database systems Concepts. Mcgraw- Hill Company.

Lee, J., Kim, Y., \& Kim, M. (2006). Effects of managerial drivers and climate maturity on knowledgemanagement performance: Empirical validation. Information Resources Management Journal, 19(3), $48-60$.

Pariskshit, N., Mahalle, B., Anggorojati, N. R. P., \& Ramjee, P. (2014). A Fuzzy Approach to Trust Based access Control in Internet Of Things. Retrieved March 10, 2015 from 
http://vbn.aau.dk/files/77649193/VITAE_D_TRUST_13.pdf

Patnaik, A. R., Srivastava, A. G., \& Nayak, A. R. (2006). Biulding Flexible Model For E- commerce applications Retrieved Novermber 21, 2013, from http://tecsis.ca/2Trust\%20model.pdf

Pavlou, P. A., \& Dimoka, A. (2006). The Nature and Role of Feedback Text Comments in Online Marketplaces: Implications for Trust Building, Price Premiums, and Seller Differentiation. Information Systems Research, 17, 392-414.

Peyman, A, Akbar, R., \& Gholamhossein, M. (2013). Developing a Model for Knowledge Sharing in Research Centres. Vine. The journal of Information and Knowledge Management Systems, 42(3), 357-393.

Rhoades, L., \& Eisenberger, R. (2002). Perceived organizational support: A review of the literature. Journal of Applied Psychology, 87(4), 698-714. http://dx.doi.org/10.1037//0021-9010.87.4.698

Rosenstock, I. M. (1966). Why People Use Health Belief Model: Milbank Memorial Fund Quarterly, 44, 94-124. http://dx.doi.org/10.1111\%2Fj.1468-0009.2005.00425.x

Rosenstock, I. M. (1974). Historical Origins of the Health Belief Model". Health Education Monographs, 2, 1-8. http://dx.doi.org/10.1037/0278-6133.11.3.190

Saqib, M., Syed, M. J. I., Saif, ur R. K., \& Choi, S. L. (2014). An Incorporated Structure of Perceived Organizational Support, Knowledge-Sharing Behavior, Organizational Trust and Organizational Commitment: A Strategic Knowledge Management Approach. Pakistan Journal of Commerce and Social Sciences, 8(1), 42- 57.

Shore, L. M., \& Shore, T. H. (1995). Perceived organizational support and organizational justice. In R. S. Cropanzano \& K. M. Kacmar (Eds.), Organizational Politics, Justice, and Support: Managing the Social Climate of the Workplace (149-164). Westport, CT: Quorum Books.

Strecher, V. J., \& Rosenstock, I. M. (1997). The Health Belief Model, In K,Glanz, K. R. M, Lewis, and Rimer, B. (Eds). Health behaviour and Health education (pp. 41-59), San Francisco CA: Jessey-Bass Publishers.

Taylor, S., \& Todd, P. A. (1995). Understanding Information Technology Usage: A Test of Competing Models. Information Systems Research, 6(2), 144-176. http://dx.doi.org/10.1287/isre.6.2.144

Teo, T. (2005). Meeting the challenges of knowledge management at the Housing and Development Board. Decision Support Systems, 41(1), 147-159. http://dx.doi.org/10.1016/j.dss.2004.05.013.

Venkatesh, V., \& Davis, F. O. (2000). A Theoretical Extension of the Technology Acceptance Model: Four $\begin{array}{llll}\text { Longitudinal Field Studies. } & \text { Management }\end{array}$ http://dx.doi.org/10.1287/mnsc.46.2.186.11926

Virgina, D., \& Rogier, M. V. (2005). Towards a model to understand the influence of trust in knowledge sharing Decision. $\quad$ Retrieved August 12, 2013, from http://igitur-archive.liberary.uu.nl/math/2006-0726200751/diagram_05_towards_model to understand.pdf

Xu, G., Feng, Z., Wu, H., \& Zhao, D. (2007). Swift trust in Virtual temporary system: a novel based on the Dempster- Shafer theory of belief functions. International Journal of Electronic Commerce, 12(1), 93-126. http://dx.doi.org/10.2753/JEC1086-4415120101

Zadjabbari, B., Mohseni, S., \& Wongthongtham, P. (2009). Fuzzy logic based model to measure knowledge sharing, in Okyay Kaynak and Mukesh Mohania (ed), International Conference on Digital Ecosystems and Technology (DEST 2009), Jun 1 2009, 507-510. Istanbul, Turkey: IEEE.

Zadjabbari, B., Wongthongtham, W., \& Hussain, F. (2010) Ontology Based-approach in Knowledge Sharing Measurement. Journal of Universal Computer Science, 16(6). http://dx.doi.org/10.3217/jucs-016-06-0956.

\section{Copyrights}

Copyright for this article is retained by the author(s), with first publication rights granted to the journal.

This is an open-access article distributed under the terms and conditions of the Creative Commons Attribution license (http://creativecommons.org/licenses/by/3.0/). 